GRINKER, Roy Richard. 2010. Autismo: um mundo obscuro e conturbado. Tradução de Catharina Pinheiro. São Paulo: Larrousse do Brasil. 320pp.

\title{
Soraya Fleischer
}

Departamento de Antropologia, Universidade de Brasília

Em 1994, o diagnóstico estimativo era de que havia três crianças autistas em cada 10.000 crianças. Em 2004, apenas uma década depois, essa estimativa era de 60 
casos para 10.000 crianças. É com este dado estatístico que Roy Richard Grinker, antropólogo da George Washington University, inicia seu livro, Autismo: um mundo obscuro e conturbado,traduzido e lançado no Brasil em 2010. O aumento surpreendeu o público americano, segundo o autor, a ponto de o Congresso Americano, à época, anunciar que se tratava de uma "epidemia" de autismo que "estava devastando as famílias" (:11).

Grinker nos pergunta: Por que esse "diagnóstico" é maior na Europa e nos EUA? Estamos diante de novas fórmulas para definir as estatísticas? As estatísticas do início dos anos 1990 eram pouco realistas? Ou estamos lidando, agora, com diagnósticos mais precisos e atualizados? Por que chamar de "epidemia" uma doença que não é contagiosa? O autor aceita o desafio de pensar esses "crescentes" números e, com o apoio da pesquisa antropológica e comparativa, chega à importante conclusão de que "não podemos afirmar que houve um aumento da incidência do autismo" (:15), e sugere que esses novos números "reflitam uma mudança na forma como nossa cultura percebe uma condição específica de saúde e doença" (:13).

Grinker analisa as ferramentas diagnósticas da psiquiatria ao longo de sua história. Volta ao século XIX, com o médico austríaco Leo Kanner (18941981), que começou trabalhando com psiquiatria em asilos nos EUA (:47) e logo se tornou expoente crítico do confinamento, da imprecisão dos diagnósticos e dos rótulos desumanizadores (:51). Foi ele quem descreveu o autismo e mudou o quadro de "sintoma" para "síndrome". Depois, outro austríaco, Hans Asperger (1906-1980), passou a usar o termo autismo para um "espectro de distúrbios", no qual também estaria incluído o "distúrbio de Asperger". "Desde o início, Asperger estava convencido de que o autismo era resultado de uma relação entre fatores biológicos - genéticos - e fatores ambientais. 'A predisposição - ele escreveu - não é um destino, mas um destino possível'" (:68). O primeiro "foi o pai do autismo como distúrbio diagnosticável", enquanto o segundo, "o pai do autismo como espectro de diferentes estados" (:70). Mas, na opinião de Grinker, a grande contribuição não foi terem descoberto, mas sim descrito o autismo, pois afinal este "não era um distúrbio novo" (:76).

Já em meados do século XX, "pais ausentes e mães más" passam a ser razões para o autismo, segundo a psicanálise de Bruno Bettelheim. Embora, como Kanner e Asperger, psiquiatras e psicanalistas da segunda metade do século XX tenham chegado a um razoável consenso de que o autismo é tanto biológico como ambiental, as mães frias demais ("a hipótese da mãe geladeira") ou apegadas demais ainda reforçam, no final do século $\mathrm{XX}$, "a crença de que as experiências da primeira infância dominam a vida adulta do indivíduo" (:98), especialmente em países como a França e a Argentina, em que a psicanálise teve papel importante na sociedade.

De um subtipo de esquizofrenia, o autismo transformou-se em um produto de pais negligentes e, depois, em uma anomalia neural. Contribuíram para essa transição o surgimento de tratamentos biológicos (como lobotomias, eletrochoques, medicamentos etc.) para doenças psiquiátricas nos anos 1940 e a padronização diagnóstica através dos sucessivos DSMs (Manual Diagnóstico e Estatístico de Transtornos Mentais). Embora este compêndio enciclopédico de diagnósticos pareça definir melhor as especificidades de distúrbios psíquicos, o autor nos lembra como ainda há falta de método, imprecisão e sensacionalismo, inclusive no caso do autismo. Pior, o DSM tornou-se uma "bíblia", deixando 
pouco espaço para o próprio terapeuta, que trabalha diretamente com a criança, chegar às suas conclusões. E a pretensa certeza universalizante, proposta pelo DSM, torna-se autoritária e improvável porque, como lembra Grinker, "os genes relacionados às doenças geralmente constituem apenas fatores de risco e não causas diretas. As predisposições genéticas interagem com a vida que levamos e essas interações podem afetar a manifestação da doença. [...] Os distúrbios do espectro do autismo são mais complicados ainda, já que anomalias de quase todos os cromossomos já foram associadas a esses distúrbios" (:130-1).

E, mais importante, a psiquiatria não é uma ciência $100 \%$ genética (ainda).

Segundo Grinker, o diagnóstico nessas áreas "psi" é sempre subjetivo, sobretudo no caso do autismo, que não é possível observar pela análise microscópica, mas sim por meio do comportamento e do contexto do indivíduo. As revisões dos DSMs têm incluído e ao mesmo tempo excluído elementos para o diagnóstico do autismo. E o autor nos lembra como essas mudanças repercutem na elaboração das estatísticas.

Assim, Grinker concorda que o autismo é um distúrbio cerebral que "pode afetar pessoas de qualquer cultura" (:21). Por um lado, "a doença pode ser biológica, mas nunca é somente biológica" (:24) e, por outro, é culturalmente definida, já que, "muitas sociedades, por exemplo, sequer possuem uma palavra para denominar o autismo, enquanto em outras os sintomas do autismo não são considerados anômalos, ou são vistos como divinos e espirituais" (:13). A partir daí, ele define sua posição: "Este livro trata da forma como a cultura afeta a nossa visão sobre o autismo. Ele analisa o autismo como fenômeno global e o observa não apenas como um distúrbio biológico, mas como um grupo de sintomas que se tornam especialmente expressivos em determinadas épocas e lugares" (:21-2).

O livro, dividido em duas partes, trata primeiro do "processo pelo qual o autismo tornou-se um distúrbio amplamente diagnosticado nos EUA" (:22) ao rever a história recente das áreas "psi" e, segundo, apresenta os resultados de pesquisa etnográfica realizada em três países - Índia, Coreia do Sul e África do Sul. A expectativa foi de que outros contextos culturais diversificassem os entendimentos sobre o autismo para, ao mesmo tempo, refletir sobre como os EUA, seu país de origem, tem lidado com a questão. Na Índia, o indivíduo autista é tido como "retardado mental" ou "louco". Há poucos psiquiatras e o autismo é mantido como segredo de família. Só em 1999 o governo indiano reconheceu o autismo como um diagnóstico. Grinker notou o que chamou de "disjunção" entre médicos - desatualizados - e pais - cada vez mais bem informados e empoderados, sobretudo pela internet e pelas redes sociais virtuais. Contudo, não há uma pressão coletiva por serviços e educação especializada. O estigma, e muitas vezes a misoginia, leva sobretudo as mães a procurarem ajuda para seu filho individualmente.

Na Coreia do Sul há muita vergonha: "Muitas vezes os autistas são escondidos e com isso acabam ficando sem tratamento e raramente são integrados na vida comunitária" (:246). Há pouca política educacional e uma grande expectativa de que as mães possam "controlar" seus filhos. Não deixa de ser paradoxal que o país, com uma altíssima exigência em relação ao "sucesso" intelectual dos filhos, não tenha desenvolvido programas educacionais apropriados para crianças diferentes. Ao contrário, essa ênfase no sucesso só acirra a discriminação em relação à diferença. Já na África do Sul, uma criança fisicamente normal mas com 
algum comportamento estranho pode passar despercebida e ser classificada como indisciplinada ou possuída por um espírito mau, mas "frequentemente não são vistas apenas como deficientes" (:266). Ali, o autismo é uma "doença invisível".

A etnografia nos três países foi quase toda realizada com mulheres. Sejam sul-coreanas, sul-africanas, indianas ou estadunidenses são as mulheres que se responsabilizam pelo cuidado com as crianças e os adultos autistas. E não é difícil chegar à conclusão de Grinker: "Quando essas mulheres se abriram comigo, tornou-se claro que na maior parte do tempo sentiam-se como mães solteiras" (:269).

Entretanto, a inflação dos "casos" e os respectivos "números" não podem ser unicamente vistos como pânico coletivo em relação à diferença. Grinker é muito feliz ao mostrar no livro como esse aumento de casos e também de diagnósticos mais específicos é oportuno para se alcançar mais visibilidade sobre o autismo e, como consequência, a elaboração de políticas públicas, pesquisas, aceitação social e assistência adequada, principalmente em termos de educação e atendimento de saúde. Em suma, essa pseudoepidemia pouco a pouco ajuda a dirimir o estigma.

Não foi rápido ou simples escrever este livro. Não foi mais uma pesquisa de campo em três países distantes. Roy Grinker tem uma filha autista e só depois de muitos anos de aprendizado como pai de uma criança autista é que ele percebeu que seria capaz de escrever sobre essa realidade. Por muito tempo ele e a esposa peregrinaram por consultórios de pediatras, psiquiatras, fonoaudiólogos, linguistas, advogados, juízes, diretores de escola e secretários municipais de Educação. Entender as especificidades da filha, Isabel, tornou-se uma prioridade naqueles primeiros anos da década de 1990. Se ela tivesse nascido antes disso, provavelmente, nos conta o autor, teria recebido um "rótulo" de esquizofrênica ou de retardada mental e possivelmente seria uma "doença a ser escondida" (:44). Se tivesse nascido depois disso, teria sido mais fácil, talvez, definir o problema e encontrar soluções em termos de medicação, escolas e apoio. Ao menos no início dos 90 foi-lhes oferecido o termo "autista" como "um comportamento a ser tolerado" (:44).

É corajoso e generoso como o autor nos apresenta sua experiência como paipesquisador, revelando detalhes do cotidiano da família Grinker, os seus dilemas e a solidão. Em suma, "defender o filho parece um trabalho em tempo integral: requer escrever cartas, fazer telefonemas, comparecer a reuniões e compilar dados com seus médicos ou terapeutas a fim de compor um caso para exigir aquilo que você acredita que o seu filho precisa" (:276). Vale lembrar, por fim, que foi fácil e um pouco emocionante encontrar no You Tube um pequeno filme em que Isabel Grinker aparece proferindo seu discurso como oradora da formatura no ensino médio.

Como bom etnógrafo, o autor nos apresenta inúmeras passagens de relações cotidianas nas famílias e vizinhanças, de preconceito e até abjeção e desespero. Contudo, grande parte do livro se dedica a observar como acontece a "inclusão" de meninas e meninos no espectro do autismo nos quatro países, sobretudo na educação formal. E por isso, ao final, o autor conclui que "é indiscutível que o autismo, como qualquer condição médica, faz parte de uma complexa estrutura de relações entre profissionais e pautas políticas" (:286). E, nesse sentido, se uma maior precisão diagnóstica tende a aumentar o número de casos (resultando na sensação de "epidemia" [sic, como 
diria Grinker]), também pode contribuir para uma maior visibilidade desses distúrbios, acabar com a vergonha, o silêncio e a solidão e "permitir dar início a um processo de integração dos autistas - e de outros deficientes e diferentes - em nossa sociedade" (:300).

O livro, feito a partir da reflexão e da pesquisa antropológica, visa a um público mais amplo, o que é ótimo. Mas peca por não ter introduzido ao pé da página ou ao final dos capítulos a bibliografia que foi apenas citada livremente. Isto dificulta que estudiosos e também familiares de autistas encontrem literatura complementar. E os autores, que só eventualmente aparecem ao longo do texto, se reduzem à antropologia médica estadunidense. Talvez pelo fato de ter sido traduzido e lançado no Brasil por uma editora voltada para temas de autoajuda o livro demore um pouco mais para chegar aos antropólogos. Ainda assim, sem dúvida, o estudo de Roy Grinker poderá ser bem acolhido entre os estudiosos da antropologia da saúde, do corpo, da ação, das políticas públicas de saúde e também da infância e educação. 